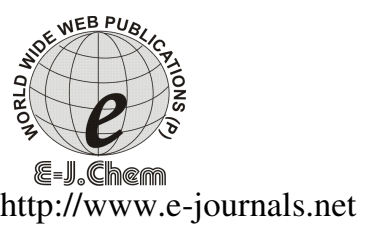

\title{
Solvent-free Synthesis of Nitriles from Aldehydes Catalyzed by KF/Al2O3, Montmorillonite KSF and K10
}

\author{
LI-JUN LI, * YING-XIA SONG, YAN-SU GAO, \\ YAN-FENG LI and JIAN-FENG ZHANG \\ College of Chemistry and Environmental Science, \\ Hebei University, \\ Baoding 071002, Hebei Province P. R. China.
}

Received 7 March 2006; Accepted 5 May 2006.

\begin{abstract}
Multistep and one-pot conversion of aldehydes to nitriles were carried out conveniently with out solvent using $\mathrm{KF} / \mathrm{Al}_{2} \mathrm{O}_{3}$, montmorillonite $\mathrm{KSF}$ and $\mathrm{K} 10$ as catalyst, under microwave irradiation. The reactions are completed within 6-8 min to give satisfactory yields. $\mathrm{KF} / \mathrm{Al}_{2} \mathrm{O}_{3}$ was more effective catalyst both in multistep procedure and one-pot reaction.
\end{abstract}

Keywords: aldehydes, nitriles, aldoximes, microwave irradiation

\section{Introduction}

Nitriles are very useful starting materials for the synthesis of various bioactive molecules. ${ }^{1}$ The versatile nitriles are used for the preparation of thiazoles, 2-oxazolines, tetrazoles, imidazoles, triazoles and benzamidines possessing a broad spectrum of biological activities. ${ }^{2}$ The conversion of nitriles into amides, amines, ketones, carboxylic acids and esters are of considerable interests. ${ }^{3}$

The conversion of aldehydes into the corresponding nitriles is an important organic transformation. This procedure is usually achieved by dehydration of the corresponding aldoximes using classical reagents ${ }^{4}$ or new milder ones such as phosphorus diiodide, ${ }^{5}$ trichloro-acetyl chloride, ${ }^{6}$ chlorosulfonyl isocyanate, ${ }^{7}$ or chlorosulfonyl fluoride. ${ }^{8}$ Bejoy 
Thomas $^{9}$ has reported conversion of aldehydes oxime into nitriles using solid acid as catalysts, but it needs high temperature and long reaction time. Recently, some one-pot transformations of aldehydes to nitriles by using various chemical reagents are also reported. ${ }^{10}$ Efficient one-pot methods were also developed using hydroxylamine hydrochloride and formic acid, ${ }^{11}$ selenium dioxide, ${ }^{12}$ pyridine in refluxing toluene, ${ }^{13}$ or from nitroethane in the presence of sodium acetate buffer ${ }^{14}$ or pyridine hydrochloride. ${ }^{15}$ Das $^{16}$ has reported microwave assisted rapid conversion of aldehydes into nitriles using silica gel supported $\mathrm{NaHSO}_{4}$ and $\mathrm{NH}_{4} \mathrm{OAc}$ catalysts. However, neither of these catalysts can be recovered. The first catalyst, which could not be stored for a long time should be prepared at the time of use and the second catalyst, which decomposed under microwave irradiation should be used in a large amount. ${ }^{17}$ Most of these known methods suffer from significant drawbacks, which include toxic and non-available reagents, harsh reaction conditions, low yields and long reaction time.

We had reported that solid acids $\mathrm{KF} / \mathrm{Al}_{2} \mathrm{O}_{3}$ Montmorillonite $\mathrm{KSF}$ and $\mathrm{K} 10$ can be used to catalyze many organic reactions. ${ }^{18}$ Here we report these three catalysts be used to convert aldehydes into the corresponding nitriles under microwave irradiation, in a simplified, rapid way, generally in excellent yield. Both the one-pot conversion and multistep procedure was studied.

\section{Experimental}

Melting points were uncorrected. Montmorillonite KSF and K-10 were purchased from Aldrich and activated at $120{ }^{\circ} \mathrm{C}$ for $3 \mathrm{~h}$ prior to use. $\mathrm{KF} / \mathrm{Al}_{2} \mathrm{O}_{3}$ was prepared by literature method. ${ }^{19}$ 4-methoxybenzaldehyde oxime and 4-hydroxybenzaldehyde oxime were synthesized according to literature, ${ }^{20}$ melting point data agree to the reported. Liquid aldehydes were purified by distillation prior to use. Other chemicals were commercially purchased and used as received. Microwave irradiation is performed in a Galanz WG900DSL23-K6 microwave oven with a nominal power of 900W. ${ }^{1} \mathrm{H}$ NMR spectra were measured on a Bruker AVANCE (400 MHz) spectrometer using TMS as internal reference and $\mathrm{CDCl}_{3}$ or DMSO as solvent.

\section{General Procedure}

\section{Aldoximes Dehydration Under Microwave Irradiation}

p-Anisaldehyde oxime $302.3 \mathrm{mg}$ ( $2.0 \mathrm{mmol}, 1 \mathrm{~b})$ were mixed thoroughly with catalyst (100 $\mathrm{mg}$ ) in a flask, then the mixture was placed inside microwave oven, and irradiated at designated power for $6 \mathrm{~min}$. Then the reaction mixture was taken out, cooled and extracted with ethyl acetate $(3 \times 10 \mathrm{ml})$. After filtration, the filtrate was concentrated and purified by column chromatography over silica gel, using petroleum ether and ethyl acetate as eluent to afford $p$-methoxybenzonitrile (1c). The results were summarized in Table 1 .

$p$-Methoxybenzonitrile (1c), m.p. $57-58{ }^{\circ} \mathrm{C}$; $\mathrm{NMR} \delta_{\mathrm{H}}\left(400 \mathrm{MHz}, \mathrm{CDCl}_{3}\right): 3.881(\mathrm{~s}, 3 \mathrm{H}$ CH3O), 6.977 (d, 2H, ArH), 7.599 (d, 2H,ArH)

\section{One-Pot Synthesis Under Microwave Irradiation}

p-Hydroxybenzaldehyde $244.2 \mathrm{mg}(2.0 \mathrm{mmol}, \mathbf{2 a})$ and hydroxylamine hydrochloride 166.8 $\mathrm{mg}(2.4 \mathrm{mmol})$ were mixed thoroughly with catalyst $(100 \mathrm{mg})$ in a flask, the mixture was placed inside a microwave oven, and irradiated for $6 \mathrm{~min}$. Then the products were cooled 
and extracted with ethyl acetate $(3 \times 10 \mathrm{ml})$. After filtration the filtrate was concentrated and the residue was purified by column chromatography over silica gel using petroleum ether and ethyl acetate as eluent to afford p-hydroxybenzonitrile (2c). The results were summarized in Table 2 .

p-Hydroxybenzonitrile (2c), m.p. $110-112{ }^{\circ} \mathrm{C}$; NMR $\delta_{\mathrm{H}}\left(400 \mathrm{MHz}, \mathrm{CDCl}_{3}\right): 6.014(\mathrm{~s}$, $1 \mathrm{H}, \mathrm{OH}), 6.954$ (d, 2H, ArH), $7.558(\mathrm{~d}, 2 \mathrm{H}, \mathrm{ArH})$

\section{Results and Discussion}

As shown in Scheme 1 and Table 1, two aromatic aldehydes, $p$-anisaldehyde (1a) and $p$ hydroxybenzaldehyde (2a), was transferred to its oximes, ${ }^{20}$ and then $\mathbf{1 b}$ and $\mathbf{2 b}$ was treated with different catalysts under irradiation of microwace to give aromatic nitriles in $28-76 \%$ yield respectively. The dehydration procedure was done with a solvent-free system and the reaction was usually completed within 8 minutes. Three kinks of catalyst, montmorillonite $\mathrm{KSF}$, montmorillonite $\mathrm{K} 10$ and $\mathrm{KF} / \mathrm{Al}_{2} \mathrm{O}_{3}$, were investigated in this reaction. $\mathrm{KSF}$ and $\mathrm{K} 10$ shown similar activity, gave out lower yield (20-38\%), while $\mathrm{KF} / \mathrm{Al}_{2} \mathrm{O}_{3}$ was more effective in this dehydration, gave out $76 \%$ and $36 \%$ yield in p-anisaldehyde oxime (1b) and $p$ hydroxybenzaldehyde oxime (2b) case, respectively.

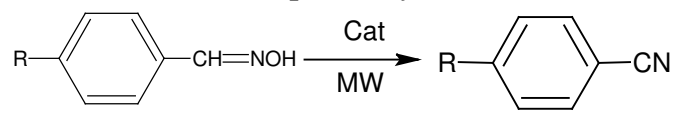

b

c

1, $\mathrm{R}=\mathrm{MeO} ; 2, \mathrm{R}=\mathrm{OH}$

Scheme 1.

In order to obtain higher yield of nitriles and avoid the troublesome separation of oxime, a one-pot conversion of $p$-hydroxybenzaldehyde (2a) to p-hydroxybenzonitrile (2c) was investigated. The reaction was catalyzed by montmorillonite KSF, $\mathrm{K} 10$ and $\mathrm{KF} / \mathrm{Al}_{2} \mathrm{O}_{3}$, with similar solvent-free condition in 6 minutes (Scheme 2), gave out $63 \%, 67 \%$ and $70 \%$ yield respectively. Compare with the same product in Table 1, it's obvious that the one-pot conversion gave out higher yield with different catalysts among the three catalysts; $\mathrm{KF} / \mathrm{Al}_{2} \mathrm{O}_{3}$ was proved to be the most effective catalyst once again in the one-pot procedure.

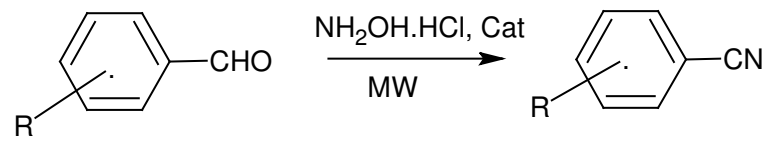

Scheme 2 .

Table 1. Aldoximes Dehydration Under Microwave Irradiation

\begin{tabular}{cccccc}
\hline \multirow{2}{*}{ Entry } & $\mathrm{R}$ & Catalyst & $\mathrm{t} / \mathrm{min}$ & $\begin{array}{c}\mathrm{MW} \\
\text { power } / \\
\%\end{array}$ & $\begin{array}{c}\text { Yield/ } \\
\%\end{array}$ \\
\hline \multirow{2}{*}{1} & $\mathrm{OMe}$ & $\mathrm{KSF}$ & 8 & 100 & 28 \\
& & $\mathrm{~K} 10$ & 5 & 100 & 38 \\
& & $\mathrm{KF} / \mathrm{Al}_{2} \mathrm{O}_{3}$ & 6 & 60 & 76 \\
2 & $\mathrm{KSF}$ & 5 & 60 & 28 \\
& $\mathrm{KH} 10$ & 6 & 60 & 20 \\
& & $\mathrm{KF} / \mathrm{Al}_{2} \mathrm{O}_{3}$ & 5 & 60 & 36 \\
\hline
\end{tabular}


Table 2. One-Pot Synthesis of Nitriles Catalyzed by $\mathrm{KF} / \mathrm{Al}_{2} \mathrm{O}_{3}$

\begin{tabular}{cccccc}
\hline Entry & $\mathrm{R}$ & $\mathrm{t} / \mathrm{min}$ & $\begin{array}{c}\mathrm{MW} \\
\text { power } / \\
\%\end{array}$ & Yield/\% & m.p. (Ref) $/{ }^{\circ} \mathrm{C}$ \\
\hline $\mathbf{1}$ & $4-\mathrm{MeO}$ & 6 & 100 & 80 & $57-58(57-59)$ \\
$\mathbf{2}$ & $4-\mathrm{OH}$ & 6 & 60 & 70 & $110-112$ \\
$\mathbf{3}$ & $\mathrm{H}$ & 6 & 60 & 51 & Liquid \\
$\mathbf{4}$ & $4-\mathrm{CH}_{3}$ & 6 & 100 & 52 & $76-78$ \\
$\mathbf{5}$ & $3-\mathrm{MeO}-4-\mathrm{OH}$ & 6 & 100 & 72 & $85(85-87)$ \\
$\mathbf{6}$ & $2,4-\mathrm{diCl}$ & 6 & 100 & 42 & $58-60$ \\
$\mathbf{7}$ & $4-4-\mathrm{NO}_{2}$ & 8 & 60 & 82 & $148(149)$ \\
\hline
\end{tabular}

As shown in Table 2 , the synthesis of aromatic nitriles (1-7c) were carried out in good yields by the one-pot reaction of aromatic aldehyde (1-7a) and hydroxylamine hydrochloride without solvent, catalyzed by $\mathrm{KF} / \mathrm{Al} 2 \mathrm{O} 3$ under microwave irradiation for 6-8 minutes. Benzaldehyde (3a), p-tolualdehyde (4a) and 2,4-dichlorobenzaldehyde (6a) gave out moderate yield (42-52\%), while $p$-methoxybenzonitrile (1c) and $p$-nitrobenzonitrile (7c) yield $80 \%$ and $82 \%$, in 6 and 8 minute respectively. There was no evidence for the formation of any other products. Further increasing the reaction time gave no significant improvement in yields but rather decomposition occurred. Compare with multistep method, the main advantages of the present procedure are mild conditions, higher yield, short reaction time and simple workup

\section{Conclusion}

We have developed a convenient one-pot method for conversion of aldehydes to nitriles without solvent, under microwave irridiation. Three kinds of catalyst were used for these reactions. Catalyst KF/A12O3 was more effective than montmorillonite KSF and K10, both in multistep procedure and one-pot reaction

\section{Acknowledgements}

We are grateful for financial supported from Hebei University

\section{References}

1. (a) Medwid J B, Paul R, Baker J S, Brockman J A, Du M T, Hallett W A, Hanifin J W, Hardy R A, Tarrant M E, Torley I W and Wrenn S, J. Med. Chem. 1990, 33, 1230. (b) Judkins B D, Allen D G, Cook T A, Evans B and Sardharwala T E, Syn. Commun. 1996, 26, 4351.(c) Fang C B, Hu H Z, Chin. J. Med. Chem., 12 (13), 134.

2. (a) Diana G D, Cutcliffe D, Volkots D L, Mallamo J P, Bailey T R, Vescio N, Oglesby R. C, Nitz T J, Wetzel J, Girandu V, Pevear D C, Dutko F J, J. Med. Chem. 1993, 36, 3240.(b) Fabiani M E, Drug News Perspect, 1999, 12, 207; Chihiro M, Nagamoto H, Takemura I, Kitano K, Komatsu H, Sekiguchi K, Tabusa F, Mori T, Tominnaga M, Yabuuchi Y, J. Med. Chem. 1995, 38, 353. (c) Khanna I K, Weier R M, Yu Y, Xu X. D, Koszyk F J, Callins P W, Koboldt C M, Veenhuizen A W, Perkins W E, Casler J J, Masferrer J L, Zhung Y Y, Gregory S A, Seibert K and P Isakson C, J. Med. Chem. 1997, 40, 1643. 
3. (a) Cohen M A, Sawden J and Turner N J, Tetrahedron Lett. 1990, 31, 7223. (b) Crossby J, Moiller J, Parratt J S and Turner N J, J. Chem. Soc. Perkin Trans 1. 1994, 1679. (c) Lou F T and Jeevanandam A, Tetrahedron Lett. 1998, 39, 9455.

4. Harrison I T and Harrison S, Compendium of Organic Synthetic Methods, J. Wiley and Sons, New York, 1971, 1, 460; 1974, 2, 186.

5. Suzuki H, Fuchita T, Iwasa A and Mishina T, Synthesis, 1978, 905

6. Saednya A, Synthesis, 1983, 748.

7. Olah G A, Vankar Y D and Garcia-Luna A, Synthesis, 1979, 227

8. Olah G A, Narang S C and Garcia-Luna A, Synthesis, 1980, 659

9. Thomas B, Prathapan S and Sugunan S, Microporous and Mesoporous Materials 2005, 79, 21.

10. (a) Wang E C and Lin G J, Tetrahedron Lett., 1998, 36, 4047 (b) Coskun N and Arikan N, Tetrahedron, 1999,55,11943.

11. Olah G A and Keumi T, Synthesis, 1979, 112

12. Sosnovsky G, Krogh I. A and Umhoefer S G, Synthesis, 1979, 722

13. Saednya A, Synthesis, 1982, 190

14. Karmarkar S N, Kelkar S L and Wadia M S, Synthesis, 1985, 510.

15. Dauzonne D, Demerseman P and Royer R, Synthesis, 1981, 739.

16. (a) Das B, Madhusudhan P and Venkataiah B, Synlett, 1999, 1569. (b) Das B, Ramesh C and Madhusudhan P, Synlett, 2000, 1599.

17. Srinivas K V, Reddy E B and Das B, Synlett, 2002, 625

18. (a) Duan H.-Y, Wang Z.-H., Li J-T, Li S-H, Li L-J and Li T-S, Synth. Commun., 2003, 33(11), 1867-1872. (b) Li J T, Li T-S, Li L.-J and Cheng X, Ultrasonics, Sonochem., 1999, 6(4), 199-201. (c) Li T-S, Li L-J, Lu B and Li J-T, J. Chem. Soc., Perkin Trans. 1, 1998, (21) 3561-3564. (d) Lu B, Li L.-J, Li T.-S and Li J-T, J. Chem. Res.(S), 1998, (9), 604-605. (e) Li J-T, Li T-S, Li L.-J and Yang Z-Q, Ultrasonics Sonochem., 1998, 5(2), 83-85.(f) Li L-J, Lu B, Li T-S and Li J-T, Synth. Commun., 1998, 28(8), 1439-1449.

19. Bergbreiter D E and Lalonde J J, J. Org. Chem. 1987, 52, 1601.

20. Fan N-T, Acta Armamentar, 1983, (3-4), 12. 


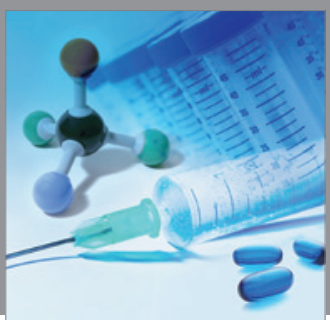

International Journal of

Medicinal Chemistry

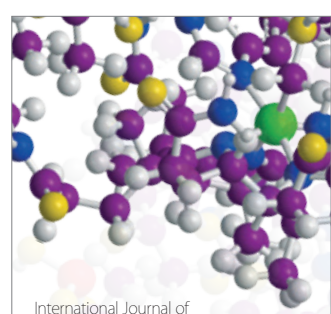

Carbohydrate Chemistry

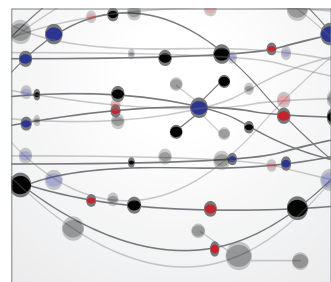

The Scientific World Journal
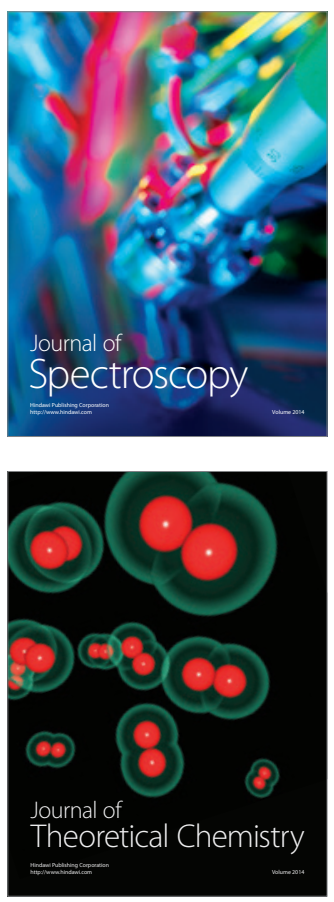
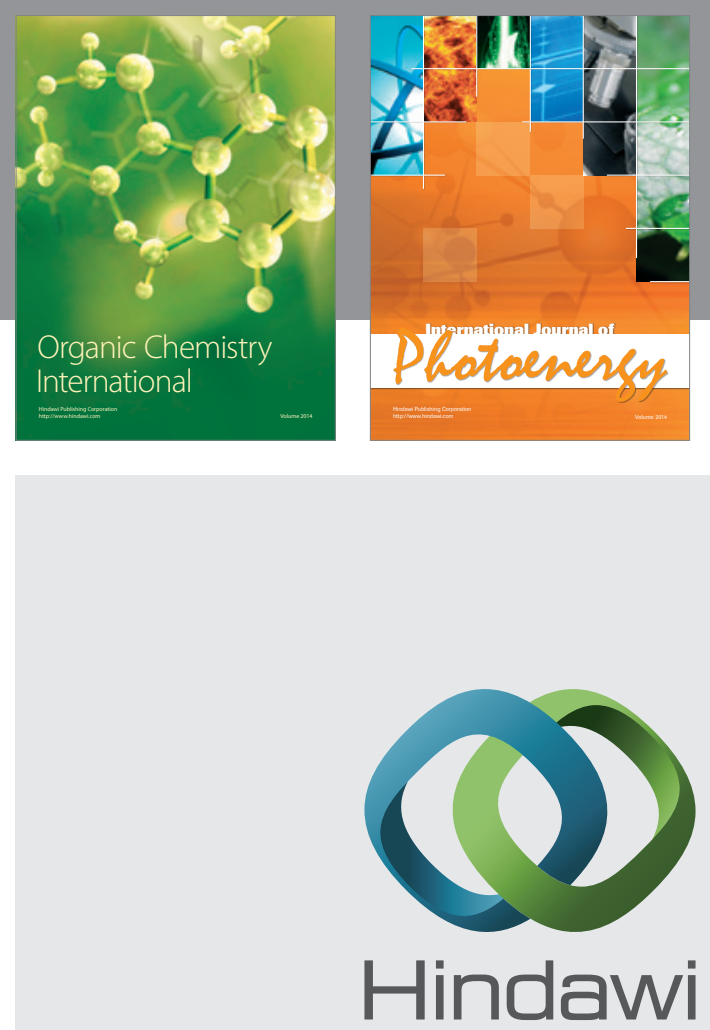

Submit your manuscripts at

http://www.hindawi.com
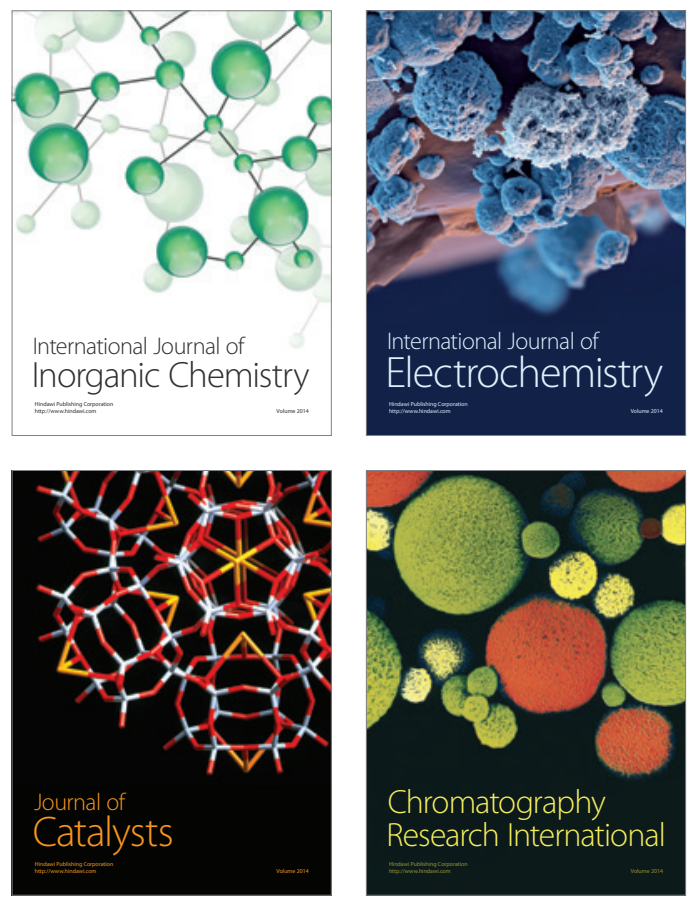
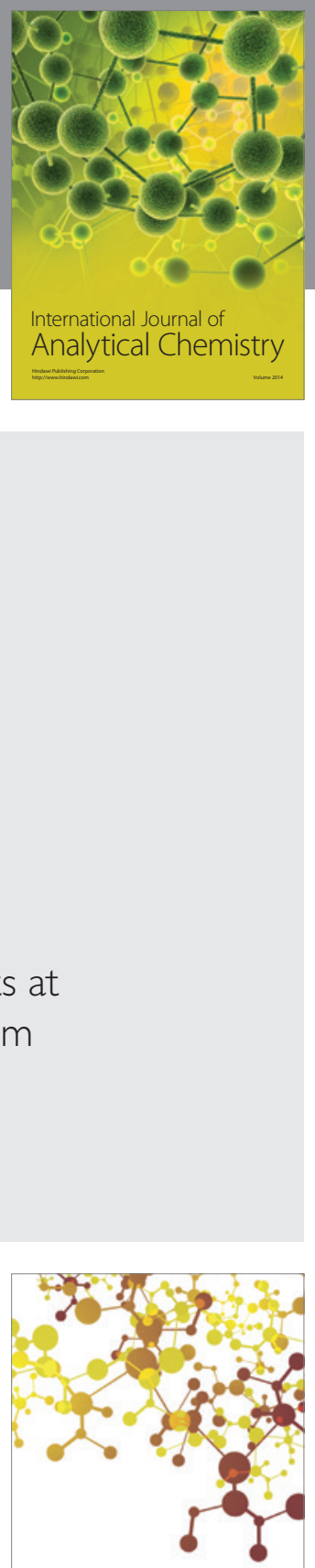

Journal of

Applied Chemistry
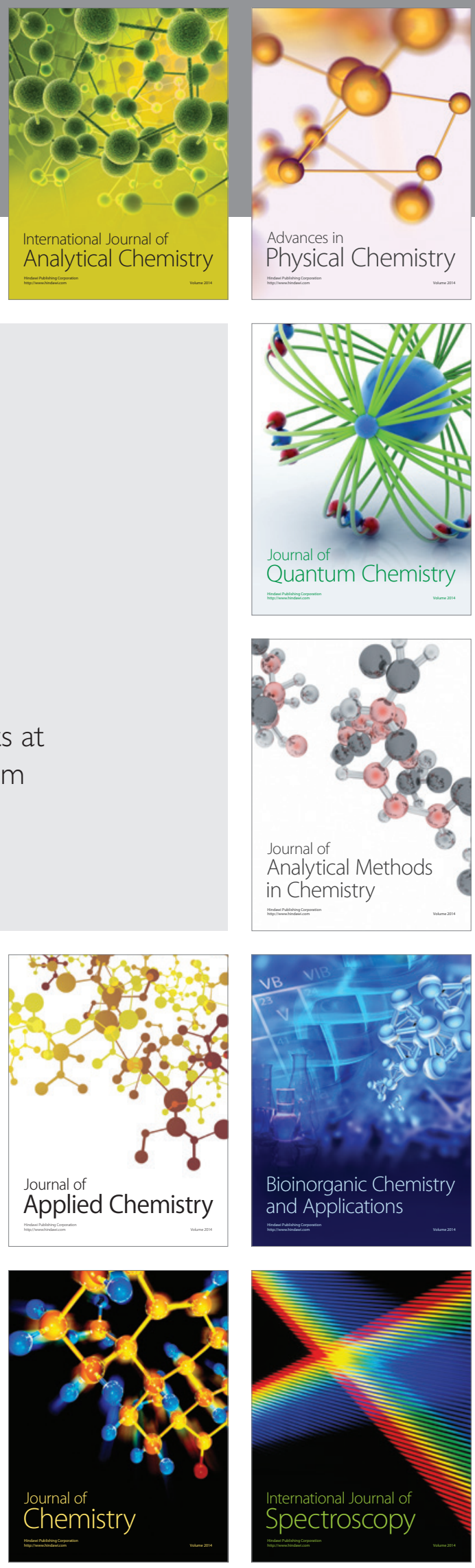